\title{
TRANSLATION AS SECONDARY COMMUNICATION. THE RELEVANCE THEORY PERSPECTIVE OF ERNST-AUGUST GUTT
}

\begin{abstract}
K. Smith ${ }^{1}$
ABSTRACT

Ernst-August Gutt started one of the greatest translation debates of the past ten years when he suggested that relevance theory holds the key to providing a unified account of translation. The bulk of the debate has been between practitioners of functional equivalence and advocates of a relevance theoretic approach to translation. However, opponents of the relevance theoretic approach have widely misunderstood Gutt's claims and objectives, with the result that too much discussion has focused on minor points of his account of translation. This article will attempt to clarify his objectives and claims, and to clear up some common misunderstandings about the implications of embracing a relevance theoretic approach to translation.
\end{abstract}

\section{INTRODUCTION}

Ernst-August Gutt contends that the phenomenon of translation is best accounted for as a form of secondary communication. He explains how translation works and lays down conditions for communicative success in translation by using the theoretical framework provided by relevance theory (Sperber and Wilson 1986 and 1995). Since the publication of his landmark book, Translation and relevance: cognition and context (1991), Gutt has become one of the most controversial and most misunderstood modern translation theorists. Although his theory has a significant contribution to make to translation theory and practice, his contribution has not been fully appreciated because of widespread misunderstanding and excessive debate about peripheral points.

The controversy centres around the challenges his work poses to the continuing validity of functional equivalence as a Bible translation method. In their eagerness to defend functional equivalence, some of its adherents have completely misinterpreted Gutt — especially with reference to the implications of his work for functional equivalence - resulting in much

1 Dr. Kevin Smith, University of Stellenbosch. 
unfruitful debate. In this paper I hope to clarify the central objective and main tenets of Gutt's thesis so as to construct a platform for constructive debate between adherents of functional equivalence and advocates of relevance theory.

\section{A UNIFIED ACCOUNT OF TRANSLATION}

The problem Gutt sought to resolve was the fact that there is no unified theory of translation that can provide a theoretically sound and practically viable explanation of how translation functions. A comprehensive account of translation needs to provide a single theoretical framework that can account for all types of translation in a unified way. This unifying theoretical framework must be able to explain the conditions for translation success in such diverse situations as, on the one hand, the translation of sacred religious texts and, on the other hand, the translation of cereal boxes and travel brochures. Furthermore, it must do so in a way that maintains internal theoretical coherence. At some level, in spite of its many diversities, translation must be understandable as a single phenomenon that is governed by the same overarching principles, whether it be Bible translation or brochure translation.

Until the advent of relevance theory, such a unified account of translation had remained elusive. Previous translation theories, such as functional equivalence, failed on two fronts. Firstly, they failed to provide an equally valid account of the diverse kinds of translation. Secondly, they suffered from some erroneous assumptions about the nature of communication and the conditions for successful communication in translation.

Working on the assumption that translation falls within the domain of communication, Gutt argued that relevance theory contains the key to providing a unified account of translation. Relevance theory distinguishes between descriptive and interpretive use of language.

In descriptive use, (a) the thought belongs to the speaker and (b) the speaker intends it to accurately represent reality. In interpretive use, (a) the thought belongs (originally) to someone other than the speaker and (b) the speaker intends his/her utterance to accurately represent the original thought. Someone speaking descriptively intends to be faithful to reality; someone speaking interpretively intends to be faithful to the meaning of the original speaker (Smith 2000:39).

Translation, then, is a form of secondary communication. Translation is the interlingual interpretive use of language in which the translator tries to 
faithfully express the thoughts of the original author in another language. Since this is true of all forms of translation, the notion of interpretive use provides the common denominator that enables Gutt to offer a unified account of translation.

Treating translation as interlingual interpretive use of language has two important consequences for the development of a comprehensive account of translation. Firstly, it enables such an account to exclude a kind of translation that has posed major problems to the development of a comprehensive account, namely, covert translation (see Gutt 2000:47-68). Covert translation is defined as "a translation which enjoys or enjoyed the status of an original ST [source text] in the target culture" (House 1981:194, quoted in Gutt 2000:47). When it comes to translating advertisements, travel brochures, and manufacturer's manuals, what matters is not whether the translation accurately expresses the meaning of the source text, but that the translation effectively conveys the necessary information. Whether or not such a translation corresponds closely to the source text is irrelevant. The source text essentially functions as a guide for the production of an original target language text. In relevance theoretic terms, covert translations are instances of the descriptive use of language because the translators are not necessarily trying to faithfully represent the meaning of the source text, but to produce an original text. As Gutt $(2000: 218)$ puts it, "[W] hat is called for is not interpretive resemblance, but descriptive accuracy and adequacy." Since translation proper is limited to instances of interpretive use, covert translation is not truly a form of translation. Therefore, a comprehensive theory of translation need not account for covert translation.

Secondly, it enables Gutt to distinguish two very different approaches to translation - direct and indirect translation - while maintaining theoretical unity in his account of translation, because in the final analysis both approaches prove to be forms of interpretive use. Together these two approaches account for all instances of genuine translation, that is, all instances where the translator is consciously trying to convey the meaning of the source text.

These two approaches to translation are derived by analogy from the two forms of intralingual interpretive use, namely, direct and indirect quotation. Just as direct quotation endeavours to convey exactly what someone else said, so direct translation endeavours to convey all the assumptions conveyed by the source text. Similarly, as indirect quotation may settle for conveying only part of the original message, so indirect translation may settle for conveying only those assumptions of the original text that are most 
relevant to the target audience. ${ }^{2}$ The fundamental difference between the two approaches is that direct translation strives for complete interpretive resemblance, while indirect translation settles for interpretive resemblance in relevant respects.

\section{DIRECT AND INDIRECT TRANSLATION}

Since his goal is to provide a unified account of translation, Gutt (2000) does not make an in-depth attempt to spell out the details of how direct and indirect approaches to translation would work in practice. His major concern is to show that there is theoretical unity underlying the diversity of approaches, not to explicate or promote any particular approach.

In fact, Gutt does not really promote new approaches to translation at all. His real concern is to examine the phenomenon of translation as presently practised, first to find a unifying principle that undergirds all translation and then to lay down conditions for successful translation. In his thinking, direct and indirect translation are not two new approaches to be applied, but two broad categories in which existing translation methods can be analysed for communicative effectiveness. Either translators strive for complete interpretive resemblance (direct translation) or they settle for interpretive resemblance in relevant respects (indirect translation). Their translation objective, defined in terms of the desired level of interpretive resemblance, determines the conditions for communicative success and, therefore, the choice of translation methods. The principles of effective communication, combined with the translation objective, determine the conditions for success. The contribution of relevance theory is to furnish the principles of communication that help predict communicative effectiveness.

If the translation objective is complete interpretive resemblance, relevance theory lays down two conditions for communicative success, one linguistic, the other contextual. Firstly, the translation must retain all the communicative clues of the original. The linguistic properties of the source text functioned as communicative clues from which the original readers could infer the author's intended meaning. Their value lies not in their intrinsic form, but in their communicative function. Due to the structural differences between languages, it is not possible to reproduce the linguistic properties of one language in another. However, it is often possible to iden-

2 Indirect quotation or reported speech may range from an almost exact reproduction of what was originally said to a rough approximation of what was said. In the same way, indirect translations range from a high to a low degree of interpretive resemblance depending on the expectations and interests of the audience. 
tify the communicative clues of the source text and formulate receptor language equivalents that serve the same communicative function. This approach is inherently similar to that of functional equivalence, which also treats the linguistic components of the source text from a functional perspective. The emphasis relevance theory places on keeping processing effort to a minimum means the reformulated communicative clues must be natural to the idiom of the receptor language. This consideration is largely overlooked by critics of a relevance theoretic approach to translation, many of whom imagine direct translation to require some sort of word-for-word correspondence, which inevitably leads to an awkwardly phrased, hard-tounderstand translation.

Secondly, the translation must presuppose that the receptor audience will "interpret [it] in the context envisaged (by the original author) for the original audience" (Winckler and Van der Merwe 1993:54, emphasis removed). An essential implication of relevance theory is that "there is a causal interdependence between stimulus, context and interpretation" (Gutt 2000: 169). A stimulus only functions as a clue to meaning in a context. A change of context can - and often does - completely alter the meaning of a statement.

When the differences between the source language context and the receptor language context are large, some of the assumptions the source text communicated to its original readers become incommunicable in the receptor context. Functional equivalence tries to bridge the contextual gap by explicating some of the contextual implications that would not be clear to modern readers, but this technique is only partially successful. In translation, some meaning is always lost because of the structural differences between languages. If the translation assumes the receptor audience will interpret it using contextual assumptions different from those of the original readers, further loss occurs due to the contextual gap between audiences. It follows that any translation which strives to attain the highest possible level of interpretive resemblance to its source must assume the same context as the original.

Therefore, a direct translation should create the impression of reading the receptor language in the source context. The idiom should be natural to the receptor language, but inferences that the original audience would have drawn from contextual rather than linguistic clues should not be explicated in the translation.

If the translation objective is less than complete interpretive resemblance (indirect translation), the conditions for success change. Just as indirect quotation does not attempt to express all the thoughts of the quoted 
speaker, but only those that are deemed relevant to the secondary audience, so indirect translation aims to convey only those assumptions of the original text that are deemed relevant to the target audience. Once it is no longer essential to capture every nuance of meaning, the requirement that the receptor audience interpret the translation using the contextual assumptions envisaged for the original audience becomes obsolete because the relevant points can usually be conveyed in the receptor context, perhaps by reformulating some phrases to make their contextual implications explicit. What is essential for an indirect translation is to maximise relevance, that is, to spontaneously communicate maximum contextual effects for minimum processing effort. This is best done by allowing the receptor audience to interpret it using the contextual assumptions of the receptor language context.

Much confusion has arisen from the claim that an indirect translation only needs to resemble its source in relevant respects. Critics tend to infer from this statement that translators are free to alter the content of the source. Nothing could be further from the truth. The very notion of interpretive resemblance suggests that the translated text is being presented as a faithful representation of the content of the source text.

$[T]$ wo conditions are required for interpretive resemblance to occur. Firstly, one statement must be presented as resembling another. Secondly, the content of the second statement must be a valid subset, large or small, of the assumptions conveyed by the first. It does not have to convey all the original assumptions, but those it conveys must be true to the meaning of the original (Smith 2000:48).

An indirect translation is an accurate, though incomplete, representation of the content of the source text in the receptor language. Although it does not endeavour to convey all the assumptions of the source text, those assumptions it does convey must be derived from the source text.

\section{WIDESPREAD MISUNDERSTANDING}

Gutt's work has been widely misunderstood, even by some leading translators and translation theorists. The sternest opposition has come from devotees of functional equivalence who perceive Gutt's work as an attempt to undermine functional equivalence, "an elaborate, theoretically-based effort to justify" a return to formal equivalence (Wendland 1997:86). This perception betrays a broad misunderstanding of Gutt's arguments and objectives. 
Serious misunderstanding occurs on two main points. Firstly, the impression that Gutt's primary objective is to undermine functional equivalence and promote formal equivalence is based on a thoroughgoing misunderstanding of his stated objective. As mentioned above, Gutt's stated aim was to provide a unified account of how the phenomenon of translation works. By treating translation as secondary communication, he sought to explain how translation works and to lay down conditions for effective communication in translation. Relevance theory does undermine functional equivalence because it exposes as false the assumption that maximum interpretive resemblance can be achieved while presupposing the receptor context. However, relevance theory also undermines formal equivalence because the principle of relevance emphasises the importance of minimising processing effort. The awkward receptor language idiom that results from attempting formal correspondence drastically increases processing effort, causing the translation to communicate poorly with its receptor audience. If Gutt's aim was to promote a return to formal equivalence, he could hardly have chosen a less suitable theoretical framework for such an endeavour than relevance theory.

Secondly, many of Gutt's critics wrongly equate direct translation with formal equivalence. Since Gutt speaks about retaining the linguistic properties (through communicative clues) and presupposing the original context, it is easy to understand how some critics arrive at this conclusion. However, a close reading of Translation and relevance: cognition and context and admittedly the argument of the book is so complex as to require careful analysis - reveals that direct translation is quite different from formal equivalence, both in theory and in practice.

This is how Gutt defines direct translation:

A receptor language text is a direct translation of a source language utterance if and only if it purports to interpretively resemble the original completely in the context envisaged for the original (2000:171, emphasis added).

For Gutt, the defining quality of direct translation is that "it purports to interpretively resemble the original completely." In practical terms, this means that it strives for complete interpretive resemblance. Since relevance theory excludes the possibility of complete interpretive resemblance across contextual gaps, this desire for complete resemblance constrains direct translation to presume the original context. Thus the presumption of the original context is more a consequence of the main part of the definition than a central part of that definition. 
It follows from Gutt's definition that any translator whose informative intention is to convey to the receptor language readers all the assumptions the original conveyed to its readers is attempting to produce a direct translation. By this definition, almost every practising Bible translator is attempting to produce a direct translation. Gutt (personal communication) considers functionally equivalent Bible translations as attempts at producing direct translations. However, they are inadequate attempts because any attempt to obtain complete interpretive resemblance must presuppose the original context.

Direct translation differs from formal equivalence in many practical ways. Firstly, and most importantly, direct translation requires naturalness of expression, whereas formal equivalence cannot avoid awkwardness of expression. To be effective, a communicative clue must be in natural language, whether it be the source language or the receptor language. Unnatural expressions undermine effective communication in translation. Secondly, although both methods require the receptor audience to have some knowledge of the source context in order to interpret the translation correctly, they differ in the kind of knowledge they require. Direct translation only requires understanding of the sociocultural context, but formal equivalence also requires knowledge of the structure of the source language. Direct translation eliminates the need for the receptor audience to know the structure of the source language by using natural receptor language idioms. Finally, direct translation requires the translator to interpret the text before he/she can translate it, whereas formal equivalence tries to eliminate the need for interpretation by making translation a somewhat mechanical process of matching source language words and grammatical structures with receptor language equivalents. By contrast, identifying and reformulating communicative clues is an interpretive process.

\section{PRACTICAL VALUE}

Perhaps the most common criticism of Gutt has been that he fails to provide translators with anything of practical value. Malmkjær's (1992:306) remark that "if they [translators] want direct help with their everyday concerns, they should not expect to find it here" summarises such sentiments. Gutt (2000:204-205) attributes this evaluation to the tendency of these translators to think in terms of "an 'input-output' account of translation." He explains the approach as follows:

Its most central axiom appears to be that translation is best studied by systematic comparisons of the observable input and output of 
the translation process: 'input' being the original text, 'output' being the translated or target text (Gutt 2000:204).

Translation studies that employ this approach provide their readers with "a body of descriptive comparisons" from which they offer generalisations about how to handle different sorts of translation problems. Therefore, translators grow accustomed to having concrete guidelines for handling various translation decisions. Since Gutt offers no such generalisations, they naturally assume that his contribution is purely philosophical.

However, by showing that translation is a form of secondary communication that can be accounted for within the domain of communication theory, he has empowered translators to predict the conditions for effective communication in translation. This is his greatest practical contribution. Rather than providing translators with a collection of specific translation principles, Gutt has laid the foundations for a "competence-oriented" approach to translation (Gutt 2000:21-22, 205-206). The descriptive-classificatory hierarchies that functional equivalence employs are valuable, but in themselves they are not sufficient to empower translators to make the right translation decisions. If translation falls within the domain of communication, then relevance theory provides the guidance translators need to make good choices. Translators who understand the laws of effective communication can work out which rendering will communicate most effectively with the receptor audience.

If empowering translators to make right decisions is Gutt's primary contribution, his input on the translation of implicit information, especially figurative language, is a major secondary contribution. Relevance theory distinguishes two kinds of assumptions a writer can convey, namely, explicatures and implicatures. Explicatures consist of all information linguistically encoded in the text, while implicatures consist of all assumptions the author intends the readers to infer from the context. "The total set of assumptions conveyed by a text consists of the sum of its explicatures and implicatures" (Smith 2000:77).

Contrary to the code model of communication, relevance theory does not regard figurative language as a stylistic way of expressing a single thought that could have been expressed equally well in a literal statement. ${ }^{3}$ Instead, figurative language is seen as projecting a range of weak implicatures upon the subject. For example, it is not possible to reduce "the Lord

3 Admittedly, this way of viewing figurative language has now fallen out of favour with many advocates of functional equivalence, but it was central to the thinking of such notable translation theorists as Eugene Nida and John Beekman. 
is my shepherd" (Ps 23:1) to a single point of comparison between Yahweh and a shepherd, such as Yahweh is my provider, or Yahweh is my protector, or Yahweh is my leader; each of these implicatures is implicit in the original metaphor. Therefore, it is not possible to explicate metaphorical language without sacrificing some of the assumptions the original text conveyed. Explication of figurative language is acceptable in an indirect translation since the translators make no pretence of retaining all the assumptions of the source. In a direct translation, however, translators must strive to retain figurative language. Since most figures of speech rely on familiarity with the original context for their impact, the presumption that the receptor audience will interpret the translation with the original context in mind protects the translation against the danger of a communication breakdown. By furnishing readers with the contextual information the original readers would have used to interpret the figure of speech, translators can substantially reduce the processing effort required of them.

\section{SUMMARY}

By showing that the phenomenon of translation can be adequately accounted for as a form of secondary communication, Gutt has made a significant contribution to the quest for a unified account of translation. He has shown that relevance theory provides a means of predicting for the communicative success in translation, thus empowering translators to predict more effectively whether or not a given rendering will communicate effectively with the target audience.

Relevance theoretic approaches to translation are not attempts to provide a theoretical basis for returning to formal-equivalent translations. Relevance theory provides sound theoretical reasons for adapting the translation principles used to produce a translation to suit the target audience's expectations and the contextual assumptions with which the target audience will interpret a translation. Each translator is free to select the specific translation method best suited to the needs of his or her target audience and translation objective. Depending on the nature of the translation project, relevance theory can endorse anything from largely literal to fairly free translations. 


\section{BIBLIOGRAPHY}

\section{FAWCETT P}

1997. Translation and language: linguistic theories explained. Manchester: St. Jerome.

\section{GuTT E-A}

1991. Translation and relevance: cognition and context. Oxford: Basil Blackwell.

1996. Implicit information in literary translation: a relevance theoretic approach. Target 8:239-256.

2000. Translation and relevance: cognition and context, 2nd. ed. Manchester: St. Jerome.

\section{MALMKJÆR K}

1992. Review of E-A Gutt, Translation and relevance: cognition and context. Mind and Language 7:298-309.

\section{SMITH K G}

2000. Bible translation and relevance theory: the translation of Titus. Unpublished doctoral dissertation, University of Stellenbosch.

\section{SPERBER D \& WiLSON D}

1986. Relevance: communication and cognition. Oxford: Basil Blackwell.

1995. Relevance: communication and cognition, 2nd. ed. Oxford: Basil Blackwell.

\section{WENDLAND E R}

1997. A review of "relevance theory" in relation to Bible translation in SouthCentral Africa, part 2. JNSL 23:83-108.

\section{Winckler W K \& VAN DER MERWE C H J}

1993. Training tomorrow's Bible translators: some theoretical pointers. JNSL 19:41-58.

Keywords

Translation

Relevance theory

E-A Gutt

Direct translation

Indirect translation

Functional equivalence

Formal equivalence 